\title{
Facing Reality and Jumping the Chasm
}

\author{
Leonard Bickman
}

Published online: 27 December 2012

(C) Springer Science+Business Media New York 2012

This special issue is unusual in that it contains only one empirical article. We usually have several articles in our special issues, but this issue focuses on a single paper with eight commentaries. I sought out Ann Garland and her colleagues because of their experience in conducting research on usual care for children and youth in clinic settings. I asked that they produce a synthesis of what we know about usual care with a focus on specialty mental health services in the community. Our journals have many studies on the efficacy of therapy but little on the care children receive in typical clinic settings. I thought it was critical to have in one place a definitive statement about the quality and effectiveness of the services we provide to millions of youth at billions of dollars in the United States.

It is commonly accepted that our usual services may not be the best they can be but are they even adequate? Are they worth the funds we spend on them? These are big questions with not a lot of good research. But if we wait for perfect data we will never address these questions. I realize there are dangers in even raising these questions since some will say such admissions put all services at risk of not being funded. However, I have more faith in our leadership that facing this reality is the first step in improving services, not the last step.

There is a reality we need to face if we are going to make progress. We need large changes to occur because, as is revealed in this special issue, there is chasm between the services we provide and what is needed. As David Lloyd

\footnotetext{
L. Bickman ( $\square)$

Departments of Psychology and Human Development and Psychiatry, Center for Evaluation and Program Improvement, Peabody \#151, 230 Appleton Place, Nashville, TN 37203-5721, USA

e-mail: leonard.bickman@vanderbilt.edu
}

George said "Anything can be achieved in small, deliberate steps. But there are times you need the courage to take a great leap; you can't cross a chasm in two small jumps." It is time to admit to the existence of the chasm and start leaping.

\section{The Article}

A manuscript was submitted, subjected to peer review and editorial feedback and the result is the first article in this issue. The rest of this editorial refers to the Garland, HaineSchlagel, Brookman-Frazee, Baker-Ericzen, Trask, and Farley-King (2013) simply as the article. I will not summarize the article here but simply encourage you to skip the rest of the editorial and read the article. Then come back to the editorial and read it and then move on to the commentaries. Stick with this order, you will find it worth your time.

\section{The Commentaries}

I sought out commentaries on this manuscript from diverse individuals. They are not representatives of any specific group or community but people who I have worked with in the past and whose opinions I greatly respect. The commentaries include the leaders of two large mental health provider organizations, a large state agency, federal agencies, health policy researchers and two services researchers. I do not claim that the commentaries represent all the diverse opinions of the field but I am certain that you will find them provocative.

Hoagwood, Olin and Cleek provide a high-level perspective on the article. Similar to the other commentaries, the authors agree with the general conclusions of the article but expand on the conclusion that current services are not 
effective by identifying factors external to the services that are in the need of change. In this challenging commentary they support other commentaries in the need to consider mental health services in the broader context of public health care in general and the dynamic forces that are affecting general heath and mental health. They anchor their observations in the work that they have been doing in New York state. They address the provocative question of why in spite of vast improvement in knowledge about mental health services we continue to fail families and children.

DeLeon, Johnson and Witter provide another policy level perspective in their commentary. They see the problems in child mental health services through the lens of general health. They suggest that the movement in health care is away from specialists and to primary care with a medical home for all. Moreover, with the implementation of the Affordable Care Act the need for more primary care providers will increase. However, given the limited number of primary care providers and the minimal training they receive in behavioral health a solution must include integrated, coordinated and interdisciplinary care. The authors of this commentary suggest major shifts in training will be necessary as well as adoption of new technologies.

The next commentary is from multiple perspectives of persons working at two federal agencies and two research organizations. De Vourseny, Sondheimer, Drumm, Jordan, Christopher and Blau accept the findings and strategies reported in the article. They also emphasize the need for a better-trained workforce and a change in policies to provide sufficient financial support both to implement and sustain evidence based treatments. Current financing policies do not support more effective treatment approaches. They propose dedicated financing for these efforts. The authors also promote the use of new technology, especially electronic health records, but point out that behavioral health is way behind general health in this area. Moreover, while there are federal financial incentives for adopting this technology there is not yet any similar incentive for behavioral health. Maybe this is a simple cause and effect relationship that should not surprise us.

Bill Reay, an experienced and risk taking director of a large agency agrees with the conclusion of the article. However he contends that the ineffectiveness of services is a known fact in both the research and provider communities but has been ignored by the policy community. He admits to being perplexed and puzzled that this has been allowed to persist and there is not more outrage about this failure. Reay attributes this passivity to several factors including our educational system that trains clinicians who are unprepared to work in the real world with current technology and the focus on values and ideology of care instead of data. Similar to many of the other commentaries he suggests a new agenda that focuses on a broader and more ecologically valid perspective on care. Reay emphasizes that providers need to both apply and generate high quality clinical data. He notes that electronic data infrastructures need to be established to accomplish these goals.

McGuirk and Button, leaders in a large multi-site agency in New York state provide another view from the coalface. They represent the cutting edge leadership that has been attempting to improve services for children and youth for several decades. From their perspective the major barrier to progress is economic. They poignantly describe the fiscal and regulatory constraints that they work under. They note that in a study conducted in New York state showed that 24 of the 26-outpatient clinics reported routinely losing money with each unit of service provided to children and their families. They do not see the shift to managed care or primary care as a great solution based on their experience. They also note other barriers should be possible to reduce but they conclude with the need for a partnership between providers and researchers is needed for progress that is "provider and consumer guided. In my experience with them this is no abstract or idle wish" but a sincere and heartfelt desire.

Kristen Woodlock, current Acting Commissioner for the New York state office of mental health is less hopeful than I am, but probably more realistic, about achieving the changes recommended by the article. Her insightful bullet points identifies why we are "stuck" in our approach and she cogently lists five points that would lead to success. She ends on a very optimistic note challenging visionary leaders to guide us through changes in policy and practice.

The commentary by Atkins and Lakind does not dispute the problems or solutions recommended by the article but make the case that the focus should be on school based and other natural environments where youth are treated. They point out that most mental health care for children and youth occur in schools and not clinics and more effort should be focused on improving those services. This an excellent recommendation but this is tempered by the realization that many of the problems noted by the article also apply to other service environments despite some unique advantages of school based services.

Our last commentary is by Scott Bryant-Comstock, a strong advocate for reform in child and youth mental health services. The tone of this commentary is more conversational and emotional in expressing the author's disappointment of the complacency of the field in the face of ineffective services and outrage that the status quo seems acceptable. He hopes that health care reform will provide the opportunity to reconsider what we consider acceptable services. He calls for more transparency and performancebased outcome measurement incentives and the resources needed to support such efforts. 


\section{My Commentary}

Are All Children's Mental Health Services Ineffective?

Clearly there is no way to prove a universal negative. For example, we cannot ascertain that there are no unicorns. The implication of the article, and the commentaries, is that we can no longer merely assume that services are effective. Services, with the appropriate incentives and resources, need to demonstrate continuously, not in one-off evaluations, that they have evidence of effectiveness. The demand for this evidence through increased accountability, outcomes orientation, rigorous monitoring, and well-implemented evidence based treatments will only increase over time as it is happening in general health care. If specialty mental health remains passive and reactive it will continue to lose financial and political support.

\section{A Perspective of the Origins of the Current Sad} State of Services

In 1999 the American Psychologist published an essay I wrote called "Practice Makes Perfect and Other Myths about Mental Health Services". In that essay I described six widespread practices that I thought had little or no research support. I used the term myth as defined by Dictionary.com "as an unproved or false collective belief that is used to justify a social institution". In that essay I noted that I was not attempting to show that these beliefs were necessarily false, but that there was little or no scientific support for their expense.

The six myths I identified in 1999 were:

1. We can depend on experienced clinicians to deliver effective services.

2. Advanced degree programs produce more effective clinicians.

3. Continuing education improves the effectiveness of clinicians.

4. Licensing helps assure that clinicians will be effective.

5. Accreditation of health delivery organizations improves outcomes for consumers.

6. Clinical supervision results in more effective clinicians

Thirteen years ago I was able to demonstrate that these statements were indeed myths, and thus without substantial scientific support. I believe that there has not been much progress since 1999 in establishing their scientific basis. These practices are still thriving as they were in the previous century. For example, we still pay more for clinicians with experience and advanced degrees. We send practitioners to traditional brief continuing education workshops although evidence from evaluations in the medical field have demonstrated that these workshops have limited ability to affect practice without other in-place supports. While accreditation has become somewhat more rigorous there is still no body of evidence that supports the assertion that better outcomes are a result of accreditation. Finally, there has begun to be some research on the importance of clinical supervision but its ability to affect clinical outcomes in the real world is questionable.

I would add three additional myths to the six above.

7. Evidenced based treatments are just as effective in the real world.

8. Progress notes are worth the time and cost.

9. Society supports effective services.

We have learned the hard way that good and even brilliant ideas are not sufficient to improve services. On the ashes of failed interventions a new field of implementation sciences is being developed to help us understand and improve the way we implement efficacious treatments in the context of the real world. As we require more from service organizations we will need to critically examine some of the widespread practices, such as progress notes, that absorb resources without evidence that they have any benefit for our clients. Finally, as is discussed in several commentaries is the need to change the incentives for delivering effective services. Currently, services are treated as a commodity with no recognition of a quality dimension. Thus, one hour of psychotherapy is equivalent to any other hour. While there are putative quality measures such as experience and degrees I have labeled them aesthetic qualities that may look good but have no function (Bickman and Noser 1999; Bickman and Salzer 1997). In essence we do not have valid measures of quality so services are paid in arbitrary, but easily measured metrics such as hours or days. We cannot expect society to pay for more effective services until we are willing to provide systems that measure effectiveness. Our previous dependence on the mythical metrics will no longer suffice. This chicken and egg dilemma (i.e. no additional resources or incentives to measure effectiveness until we can demonstrate effectiveness) is being resolved by the handful of bold and innovative leaders in government, service organizations and the research community whom are pushing the envelope by demonstrating that it is feasible to measure quality and to improve client outcomes in the real world.

These myths help maintain the status quo with the attendant assumption that our services are just fine as long as they are delivered by licensed and experienced clinicians who attended a workshop on some evidence based training, trained in accredited schools, and delivered by accredited service organizations. Even if that were true, this would account for a tiny percentage of services. 
The Hidden Costs of the Status Quo

Compared to 1999 there are now even fewer resources for services, thus the opportunity costs of consuming resources are even more important. Are there other aspects of service provision that we should be evaluating but are not? An example that comes to mind is story told to me by one of my professors when I was a graduate student. It seems that just before the start of World War II there was increased concern about the efficiency of artillery batteries. A time and motion expert was called into observe and film a crew in action. When the expert reviewed the film he was puzzled by the action of one service member who appeared to do nothing but stand by the front right bumper of the truck that pulled the artillery piece. When he questioned the colonel about that man's function the colonel gave a very quick and precise answer. He replied that the man was there to hold the horses. ${ }^{1}$ Although the artillery had stopped using horses years before the organization failed to question this long-time practice. My question is how much is being wasted in current organizations on activities similar to holding the horses because that is how they always did business? If there are going to be fewer resources then we need to become aware of the assumptions underlying our current practices and be as rigorous in critically evaluating current practices as we do with innovations.

\section{Why is Progress So Hard to Obtain?}

I used to believe that the field was just resistant to change. But I don't think that is the case. We see lots of change in mental health services. We have a plethora of psychotherapies and the continuing education that accompanies them. We have seen massive changes at the systems level with the introduction of systems of care and its offshoot wraparound. The development of evidence based treatments is alive but maybe not as well as could be. What is missing is progress. The bottom line to me has always been are people getting better because of the services they receive. We lack evidence of real progress in children's mental health service. Garland and her colleagues offer some reasons for the lack of progress and the commentaries provide additional reasons. I think we must recognize just how difficult it is to have real progress given the complexity of our funding streams, service contexts, multiple disciplines and so on. What we do not find in the article or

\footnotetext{
$\overline{1}$ This story can be found in the introduction of a chapter by Morison, Gunfire at sea: A case study of innovation. In Morison, E. (1966) Men, machines, and modern times. Cambridge, MA: MIT Press.
}

any of the commentaries, and it is heartening, is attributing the blame for our current state to any particular sector. We see the status quo as our collective responsibility of researchers, providers, consumers and policy makers. Each has an important role to play in reform.

What I take away from the article and the commentaries is not simply a plea for more funding, but a redirection of funding to incentivize the wonderful ideas presented in this special issue. Our services and systems are far from $100 \%$ efficient. There are savings to be made in current operations. We do not need the burdensome paperwork and regulations from the past when we had no ability to monitor the quality and effectiveness of services. Although technology is just beginning to affect mental health services, and there will be many missteps at the start, I do believe it will allow us to deliver better services at lower costs (Bickman, Kelley and Athay, in press).

Three years ago Kim Hoagwood and I hosted a conference on children's mental health services at Vanderbilt University. We produced a special double issue of this journal of over 200 pages (Bickman and Hoagwood 2010). There were plans for workgroups to focus on specific activities following the conference. To the best of my knowledge none of those activities took place. In interviews with a sample of participants of this conference (Haynes 2010) there was some hope that the conference and the publication would result in some modest progress in the future. However, it is hard to determine if the conference and the publication did have any effect. Why then go through the time and effort to produce this special issue? One of the aspects of children's mental health that attracted me and kept me in this field longer than any other area I have worked in is the sense of optimism and hope that we have. While it might be characterized as delusional behavior I do see it as the major motivator for trying to improve the lives of children. A little delusion can go a long way in jumping those chasms.

\section{References}

Bickman, L., Douglas Kelley, S. \& Michele Athay, M., (In press) The Technology of Measurement Feedback Systems. Couple and Family Psychology: Research and Practice.

Bickman, L., \& Hoagwood, K. R. (2010) (Eds.) Making the Real World Ideal: Changing Practices in Children's Mental Health Services. Administration and Policy in Mental Health and Mental Health Services Research, 37(1-2), doi:10.1007/s10488010-0289-9.

Bickman, L., \& Noser, K. (1999). Meeting the challenges in the delivery of child and adolescent mental health services in the next millennium: the continuous quality improvement approach. Applied and Preventive Psychology, 8, 247-255.

Bickman, L., \& Salzer, M. S. (1997). Measuring quality in mental health services. Evaluation Review, 21(3), 285-291. 
Garland, A. F., Haine-Schlagel, R., Brookman-Frazee, L., BakerEriczen, M., Trask, E., \& Fawley-King, K. (2013). Improving community-based mental health care for children: Translating knowledge into action. Administration and Policy in Mental Health and Mental Health Services Research, 40(1). doi:10.1007/s10488012-0450-8.
Haynes, K. T. (2010). An impetus to move the field forward: a look at child and adolescent mental health services participant's views of the prospects for change. Administration and Policy in Mental Health and Mental Health Services Research, 37(1-2), 7-14. doi:10.1007/s10488-010-0289-9. 